\title{
ABUSO SEXUAL INFANTIL ATRAVÉS DE GERAÇÕES: REVISTANDO O CONCEITO DE TRANSMISSÃO PSÍQUICA NO CONTEXTO DE VIOLÊNCIA INFANTIL PELA CRÍTICA FEMINISTA
}

Child sexual abuse across generations: searching the concept of psychic transmission in the context of child violence by feminist criticism

Debora Rickli Fiuza (D) Mestre em Desenvolvimento Comunitário pela Universidade Estadual do Centro Oeste, Interdisciplinar em Desenvolvimento Comunitário,

Guarapuava, Brasil

https://orcid.org/0000-0002-4516-8937

A lista completa com informações da autora está no final da resenha

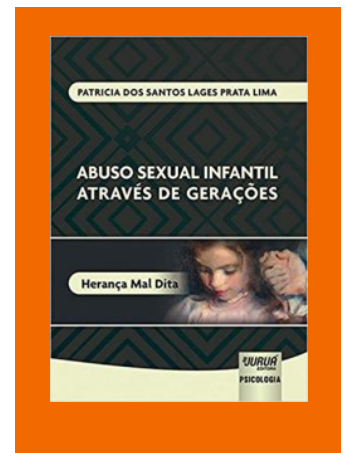

LIMA, Patrícia dos Santos Lages Prata. Abuso sexual infantil através de gerações: herança mal dita. Curitiba: Juruá, 2020.

PALAVRAS-CHAVE: Infância. Violência Sexual, Interdisciplinaridade.

KEYWORDS: Childhood. Research. Sexual Violence. Interdisciplinarity. 
O livro chamado "Abuso sexual infantil através de gerações" (2020) apresenta-se como uma obra corajosa dentro do círculo acadêmico que, inegavelmente, desperta a curiosidade de estudiosos deste fenômeno complexo, sobretudo, por encarar um tema de difícil acesso que é o abuso sexual na infância por uma perspectiva teórica exclusivamente psicológica.

O livro é fruto de uma pesquisa de mestrado defendida pela Universidade Federal de Santa Catarina (UFSC), lançado em 2020 pela editora Juruá Psicologia. A partir da prática clínica com famílias envolvidas no contexto de abuso sexual e o interesse pela pesquisa clínica, a obra discorre sobre conceitos fundamentais à luz da psicanálise de Freud e no diálogo com outros autores, como uma tentativa de compreensão da violência sexual a partir do conceito psicanalítico de transmissão psíquica. Em síntese, há um entendimento de que a existência da violência sexual em determinados grupos familiares está inscrita por um emaranhado de conteúdos inconscientes - os ditos, não ditos e mal ditos da cena de abuso sexual - que não encontrando um caminho possível de simbolização, se reatualizam em diferentes gerações, como um destino inevitável dentro do grupo familiar. É com uma perspectiva crítica sobre "a violência sexual que não escapa ao sujeito" e pelo olhar feminista que esta resenha se coloca como fonte notável de reflexão.

A obra se divide em 09 capítulos, entrelaçados pela teoria psicanalítica que exige do leitor o retorno aos textos originários de Freud. Uma leitura teórica, requerendo pausas no seu percurso e o mínimo de apreço pela perspectiva psicanalítica. No primeiro capítulo há uma pergunta: por que mulheres de diferentes gerações, pertencentes a uma mesma família, aparecem enlaçadas a histórias de abuso sexual? Nesse primeiro momento, o conceito freudiano de herança e repetição é dialogado com referências importantes da transmissão psíquica geracional como Rene Kaës, Nicolas Abraham, Maria Torok, InglezMazzarella. No segundo capítulo apresenta-se o método de pesquisa clínica pelo viés da psicanálise como o caminho de investigação. No capítulo terceiro narra-se a história de Helena e Kelly, mãe e filha adolescente de 13 anos, ambas envolvidas pelo enredo da violência sexual e protagonistas do estudo de caso. Ainda nesse capítulo, é exposto informações referentes às sessões, registros em prontuários e discussão de caso com a equipe, sobretudo, partindo da análise do pedido de Helena - a mãe - a qual chegou ao serviço após solicitação de ajuda por órgãos de proteção (Conselho Tutelar, Delegacia Especializada, Instituto Médico Legal), denunciando a violência sexual sofrida pela filha.

No quarto capítulo é discutido, de maneira mais demorada, alguns conceitos basilares da pesquisa da autora, discorrendo sobre os temas violência, incesto e de 
transmissão psíquica pelo texto clássico freudiano Totem e Tabu (1912), partindo do interesse de Freud em comprovar o horror ao incesto por povos primitivos, concluindo por meio de suas especulações que "quanto maior a proibição, maior o desejo, já que na ausência deste não há motivo para a lei interditora" (LIMA, 2020, p. 46). Ao estudar o sistema totêmico, Freud se aproxima do que ele mesmo entende por uma mente coletiva, como se uma geração carregasse a mente da sua ancestralidade.

O capítulo quinto, revisitando outros autores psicanalíticos, contemporâneos de Freud, concebe a lógica do trauma e da violência como condições constituintes do sujeito, reiterando que o trauma é inerente a condição humana, contudo, este evento não deve ocorrer pela via da violência. Para compreender os caminhos que levam ao abuso sexual, sobretudo o incestuoso, é problematizado as relações de amor e de trocas libidinais ${ }^{1}$ entre os bebês e seus cuidadores, cenário necessário para a identificação e constituição do sujeito, onde a criança coloca o seu corpo à disposição das carícias maternas. Com isso, a autora impõe alguns questionamentos: o que marcaria a passagem do uso do corpo infantil pela via das carícias para um ato abusivo? É no limite entre o normal e o patológico que a violência incide, inclusive, pela discussão do termo "consentimento da criança" para o abuso sexual, como sujeito ativo nas relações de afeto e nas relações de violência sexual. Sobre isso é merecido um olhar cuidadoso e problematizador, visto que a violência infantil está inserida em um contexto marcado pela cultura adultocêntrica e machista, onde crianças estão à mercê de condições de risco e vulnerabilidade, e seus corpos considerados propriedade irrestrita de adultos que, deveriam protegê-las e garantir uma existência segura, mas que, muitas vezes, são os perpetradores dos diferentes tipos de violência. Coutinho (2017) cita a autora Fulvia Rosemberg ${ }^{1}$ lembrando que esta foi a primeira pesquisadora a utilizar o termo "adultocentrismo" no Brasil, questionando a centralidade dos adultos frente às crianças. A partir dos apontamentos de Santiago e Faria (2015, p. 73) pela perspectiva adultocêntrica "as crianças são percebidas como inferiores em relação ao grupo dominante composto por pessoas adultas: o adultocentrismo é um dos preconceitos mais naturalizados pela sociedade contemporânea" (2015, p.73).

No capítulo sexto, a autora retoma os escritos de Freud e é pelos textos Totem e Tabu (1912-13) e Sobre o Narcisismo: uma introdução (1914), que o pai da psicanálise traça suas primeiras distinções entre a transmissão da vida psíquica pela via da identificação dos modelos parentais e a transmissão genérica que é marcada por traços Brasil.

1 A autora é referência internacional, utilizando o conceito "adultocentrismo" na década de 70 no 
advindos de outras gerações. No sétimo capítulo é discutido o enredo familiar, nas histórias de abuso sexual sofrido por Helena, sua filha adolescente Kelly e repetidas vivências de violência por outras mulheres (tias, mãe, primas), de diferentes gerações, pertencentes ao mesmo grupo familiar.

No oitavo capítulo é retratado a relação entre mãe-filha, tomando como ponto central o conceito de Complexo de Édipo por Freud e pela releitura lacaniana deste evento, analisando os conteúdos inconscientes, o histórico familiar e as dinâmicas psíquicas entre mãe e filha (concluído pela incestualidade presente nestas relações), que parece, segundo a pesquisadora, ser o ponto crucial para a compreensão do caso clínico.

O nono e último capítulo, sem a intenção de um enquadre que se esgote, seguindo as especulações teóricas sobre o incesto, a autora pressupõe que o abuso sexual sofrido pela filha adolescente Kelly, ocupava a função de um reencontro afetivo com sua mãe, revivendo as relações primordiais entre mãe-bebê. O que chama a atenção no enredo familiar, onde mulheres de diferentes gerações se apresentam fiéis a apropriarem-se do fantasma - a violência sexual reatualizada em várias gerações - é o fato de uma mulher, a mãe da adolescente, Helena, à sua maneira, atuar diferentemente do repetido na família (postura passiva diante do abuso sexual) e se posicionar contrária ao abuso da filha e aos abusos sofridos em sua própria história, como um movimento que resistiu à repetição da violência.

Embora a obra represente uma voz bastante refinada para o debate da violência infantil, a autora não foi pretensiosa em esgotar o assunto, pelo contrário, na tentativa de ampliar as lentes para um tema que é tão complexo, considerou as dinâmicas inconscientes envolvidas no contexto de abuso sexual. Ainda assim, ao longo da leitura é inegável o desconforto frente ao aparente determinismo apresentado pela teoria psicanalítica, sobretudo, ao considerar o abuso sexual como um destino inevitável para determinados sujeitos. Considerar a transmissão psíquica como principal operador na problemática da violência sexual nos pareceu frágil, porque grande parte das crianças e adolescentes envolvidas na condição de abuso sexual, bem como suas famílias, estão inseridas em contextos socioculturais que impõe um lugar de risco e vulnerabilidade à violência. Diante disso, caberia uma articulação mais potente do fenômeno da violência sexual infantil se articulado com a discussão produzida pela antropóloga Lélia González, referência na militância e na construção intelectual de um feminismo vinculado com demandas ampliadas, foi importante para a consolidação dos movimentos sociais de mulheres negras no Brasil. 
Além disso, as estatísticas mostram que crianças de classes subalternizadas e atravessadas pelo marcador de raça são as mais afetadas pela violência infantil. Mais do que uma herança psíquica, a violência sexual infantil é também resultado de uma cultura machista que considera os corpos femininos - mesmo os corpos infantis - como propriedade e uso sexual. Além do mais, uma cultura adultocêntrica que silencia as crianças vitimizadas, dificultando as denúncias e pedidos de ajuda. Exige-se, contudo, uma discussão mais contextualizada, superando a naturalização e individualização da prática da violência infantil, como algo já esperado e, até mesmo, um fenômeno "aceitável" na nossa sociedade. Discursos que amortecem a existência da violência e que reduzem a vítima a um objeto de passividade e fatalidade são ampliados, quando incluído os fatores socioculturais.

\section{REFERÊNCIAS}

LIMA, Patrícia dos Santos Lages Prata. Abuso sexual infantil através de gerações: herança mal dita. Curitiba: Juruá, 2020.

COUTINHO, Angela Scalabrin. Os novos estudos sociais da infância e a pesquisa com crianças bem pequenas. Revista Educativa, volume 9, 2017, disponível em http://seer.pucgoias.edu.br/index.php/educativa/article/view/5426/0

FREUD, S. (1913). Totem e Tabu. In: FREUD, S. Edição standard brasileira das obras psicológicas completas de Sigmund Freud. v. 13. Rio de Janeiro: Imago, 1990, p. 11-125.

FREUD, S. (1914b). Sobre o narcisismo: uma introdução. In: FREUD, S. Edição standard brasileira das obras psicológicas completas de Sigmund Freud. v. 14. Rio de Janeiro: Imago, 1990, p. 83-119.

GONZALEZ, Lélia Gonzalez. Racismo e sexismo na cultura brasileira. In: SILVA, L. A. et al. Movimentos sociais urbanos, minorias e outros estudos. Ciências Sociais Hoje, Brasília, ANPOCS n. 2, p. 223-244, 1983.

GONZALEZ, Lélia Gonzalez. A importância da organização da mulher negra no processo de transformação social. Raça e Classe, Brasília, ano 2, n. 5, p. 2, nov./dez. $1988 d$.

SANTIAGO, Flávio; FARIA, Ana Lúcia Goulart. Para além do adultocentrismo: uma outra formação docente descolonizadora é preciso. Revista Educação e Fronteiras, Dourados, v. 5, n. 13, p. 72-85, jan./ abr. 2015 


\section{NOTAS}

\section{Debora Rickli Fiuza}

Mestre em Desenvolvimento Comunitário pela Universidade Estadual do Centro Oeste, Interdisciplinar em Desenvolvimento Comunitário, Guarapuava, Brasil debora rickli@yahoo.com.br

(1) https://orcid.org/0000-0002-4516-8937

Endereço de correspondência do principal autor

Rua Almirante Didio Costa, 1719, 85070-230, Guarapuava, PR, Brasil.

\section{AGRADECIMENTOS}

Agradeço a minha orientadora Luciana Klanovicz pelo incentivo e ao meu filho João Lucas pela existência.

\section{CONTRIBUIÇÃO DE AUTORIA}

Concepção e elaboração do manuscrito: D. R. FIUZA.

Coleta de dados: D. R. FIUZA.

Análise de dados: D. R. FIUZA.

Discussão dos resultados: D. R. FIUZA.

Revisão e aprovação: D. R. FIUZA.

\section{FINANCIAMENTO}

Não se aplica.

CONSENTIMENTO DE USO DE IMAGEM

Não se aplica

\section{APROVAÇÃO DE COMITÊ DE ÉTICA EM PESQUISA}

Não se aplica.

\section{CONFLITO DE INTERESSES}

Não se aplica.

\section{LICENÇA DE USO}

Os autores cedem à Revista Internacional Interdisciplinar INTERthesis os direitos exclusivos de primeira publicação, com o trabalho simultaneamente licenciado sob a Licença Creative Commons Attribution (CC BY) 4.0 International. Estra licença permite que terceiros remixem, adaptem e criem a partir do trabalho publicado, atribuindo o devido crédito de autoria e publicação inicial neste periódico. Os autores têm autorização para assumir contratos adicionais separadamente, para distribuição não exclusiva da versão do trabalho publicada neste periódico (ex.: publicar em repositório institucional, em site pessoal, publicar uma tradução, ou como capítulo de livro), com reconhecimento de autoria e publicação inicial neste periódico.

\section{PUBLISHER}

Universidade Federal de Santa Catarina. Programa de Pós-graduação Interdisciplinar em Ciências Humanas. Publicação no Portal de Periódicos UFSC. As ideias expressadas neste artigo são de responsabilidade de seus autores, não representando, necessariamente, a opinião dos editores ou da universidade.

\section{EDITORES}

Javier Ignacio Vernal e Silmara Cimbalista

\section{HISTÓRICO}

Recebido em: 10-03-2021 - Aprovado em: 22-07-2021 - Publicado em: 19-08-2021 